\title{
Vivência de extensão em formação política pela sétima arte: o cinema como possibilidade de mobilização para aprendizagens
}

Noádia Munhoz Pereira ${ }^{1}$

\begin{abstract}
Resumo
O projeto esteve vinculado ao grupo de pesquisa "Trabalho, educação e sociedade" (GPTES), pertencente ao Programa de Pós-graduação em Educação da Universidade Federal de Uberlândia. Como objetivo geral, tem-se a construção de uma narrativa fílmica que enfatizou o aspecto socioeducacional de análise da conjuntura política educacional brasileira, considerando o país em sua perspectiva histórica de ampla tradição política. O projeto possibilitou o diálogo conceitual de cidadania e direitos humanos e se tornou, no interior da universidade, no biênio 2015/2016, recurso didático de uma prática pedagógica de ampla participação da comunidade externa à instituição. A proposta cinematográfica entrelaçou a temática central da política, trouxe a memória fotográfica e a narrativa em sua proximidade com seus impactos no âmbito da educação básica, e, portanto, contribuiu com a formação e ampliação da capacidade crítica de seus participantes. Conclui-se que, a técnica de ensino que trata da utilização de filmes didaticamente acabou por se tornar um elo no planejamento e preparação dos alunos em seus contextos de pesquisa, além de veículo de transmissão do conhecimento.
\end{abstract}

\section{Palavras-chave}

Prática Pedagógica. Cinema. Pesquisa. Formação Política.

1. Doutoranda em Educação pela Universidade Federal de Uberlândia, Minas Gerais, Brasil; membro do Grupo de Pesquisa Trabalho, Educação e Sociedade (GPTES/UFU). E-mail: noadia.pereira@ufu.br. 


\title{
Extension living in political training for the seventh art: the cinema as a possibility of mobilization for learning
}

Noádia Munhoz Pereira*

\begin{abstract}
The project was linked to the research group "Trabalho, educação e sociedade" ("Work, education and society" (GPTES), belonging to the Graduate Program in Education at Federal University of Uberlândia. It aimed to analyze the construction of a film narrative which emphasized the socio-educational aspect of the Brazilian political educational scenario analysis, considering the country in its historical perspective of a broad political tradition. The project made it possible the conceptual dialogue of citizenship and human rights, as well as, within the university, within the 2015/2016 biennium, as a didactic resource, a pedagogical practice of broad participation of the external community to the institution. The cinematographic proposal intertwined the central theme of politics, bringing the photographic memory and the narrative in its proximity to its impacts in the scope of basic education, therefore, contributed to the formation and expansion of the critical capacity of its participants. It is concluded that the teaching technique that deals with the use of films didactically ended up becoming a link in the planning and preparation of students in their research contexts, as well as a vehicle for transmitting knowledge.
\end{abstract}

\section{Keywords}

Pedagogical Practice. Cinema. Research. Political Formation.

\footnotetext{
* PhD student in Education, Federal University of Uberlândia, State of Minas Gerais, Brazil; member of the Work, Education and Society Research Group (GPTES/UFU). E-mail: noadia.pereira@ufu.br.
} 


\section{Introdução}

A pedagogia da imagem, entendida como a inserção de imagem e som com proposta pedagógica no processo educativo, se expandiu no Brasil como manual didático no final do século XIX após o surgimento da imprensa e de sua significação para a escolarização ao longo do tempo e, mais precisamente, ao longo do surgimento dos diferentes níveis de ensino. $\mathrm{O}$ compartilhamento no espaço escolar subsidiou a oralidade da leitura e da escrita, pois socializou a ascensão da escola assumindo temáticas sobre a cultura escolar e suas representações sociais mais prementes (OLIVEIRA, 2007).

Para além do projetor de slides e o retroprojetor, com a introdução da pedagogia da imagem ${ }^{2}$, acrescenta-se o monitor de televisão, o computador, o videocassete, o projetor multimídia, o episcópio, a internet, a smart board e outros com o propósito específico de investigar qual o papel do cinema na educação. Contudo, a vantagem do cinema para a formação de futuros professores se situa na expectativa de seu auxílio didático em sala de aula.

Várias vertentes a respeito de sua utilização como técnica de ensino, desde o planejamento até a preparação dos alunos para assistir a um filme, com roteiros organizados previamente têm o objetivo de situar a discussão proposta. Há, inclusive, a proposta de relatórios analíticos após a discussão de um filme, sendo sua temática proposta com antecedência, a fim de se orientar o conteúdo. (SOUZA; CARVALHO; RIBEIRO, 2013, p.11).

A linguagem fílmica se manifesta como um objeto artístico. Assim, os filmes assistidos no decorrer do projeto retrataram ênfases formais, que descreviam objetos e fenômenos com tendência à abstração clássica, sobretudo pela intensificação das emoções no limite do normal, que, por sua vez, há de se discutir a categoria estética de cada uma das películas mais adiante.

Sendo assim, a pedagogia da imagem se insere conceitualmente no planejamento espacial da aprendizagem pré-escolar e imerge, principalmente, as crianças da educação básica em um mundo de estímulos visuais/cinéticos, em que as características (formato, cor, textura, usos) dos objetos - brinquedos, blocos, telas, argila, livros, cartazes, filmes, vídeos, a imprensa escolar, lousa, ábacos e outros - são por elas interpretadas como desencadeadores de determinados enredos de ação. O projeto em questão apresenta a motivação primeira de abrir possibilidade de arranjo espacial pedagógico no âmbito da educação básica ao envolver o estímulo visual nos alunos dos cursos de graduação, em especial, os de licenciatura, já que são esses cursos que têm a incumbência de zelar pela formação de estudantes, adequando essa formação às expectativas da cultura escolar em seus diferentes prismas de criação, exploração de interesses e abordagens de conteúdos. Dessa forma, priorizou-se a proposta do conceito de política como fator preponderante para aprofundamento e empoderamento na aprendizagem, em específico, no espaço físicosocial da Universidade Federal de Uberlândia.

A apreciação da arte cinematográfica recorre, no projeto em análise, na influência marxista, que deslocou o interesse da estética formal e ideal para a estética social, cuja origem

2. Quando se defende uma incessante atividade exploratória e criativa por parte das crianças, individualmente ou em pequenos grupos, todas partilhando diferentes recursos materiais, deve haver grande preocupação com a funcionalidade e a estética dos ambientes, já que todos os espaços servem para a educação visual, expressiva, cognitiva, ética e estética. Sua organização gera uma estrutura orientadora não apenas do comportamento das crianças, mas também e dos demais membros da comunidade escolar. (OLIVEIRA, 2007, p. 194) 
se encontra no pensamento de Georg Luckács, aprofundado posteriormente por Lucien Goldmann às visões de mundo das classes sociais. Assim, o materialismo histórico pôde aprofundar as manifestações intelectuais e artísticas não apenas do exterior, mas, especialmente, do conteúdo combinado com mecanismos de mediação entre a sociedade e a obra.

De acordo com a estética sociológica abordada nas narrativas fílmicas, a perspectiva de compreensão que haveria de chegar ao público-alvo do projeto seguiria a seguinte problematização de indagação: a) quais saberes seriam mobilizados e produzidos nos debates fílmicos?; b) como as experiências formativas se configuram e se manifestam na produção dos saberes de formação dos alunos, professores e comunidade como um todo?; c) os sujeitos da comunidade se reconhecem como produtores do saber elaborado nas películas?

Tais indagações integraram os elementos constitutivos comuns da vida cotidiana de formação política dos participantes e, além disso, aproximaram contrapontos entre a memória recente, a realidade, a história e a interpretação e seus sentidos diversos postos para reflexão contínua.

\section{Relato de experiência de aprendizagem}

A onda

O filme $A$ onda explora um olhar sobre como certa ideologia pode impor e alterar valores e costumes e como isso pode influenciar o convívio escolar e familiar, levando em consideração os métodos de ensino utilizados no sistema educacional e suas influências na vida pessoal dos alunos e do professor como um todo.

A narrativa ${ }^{3}$ é baseada em fatos ocorridos em 1967 em uma escola secundária da Califórnia, nos Estados Unidos. A partir da história protagonizada por ele próprio, Ron Jones escreveu um ensaio intitulado "The third wave", que deu origem ao livro homônimo ao filme e se tornou leitura obrigatória no currículo de escolarização alemã.

A primeira cena do filme apresenta como foco o personagem principal: Rainer Wenger, ouvindo e cantando a música "Rock in rol high school" (sobre música, alienação e contestação), dos Ramones, enquanto dirige seu carro a caminho da escola em que trabalha como professor. Ao chegar, é informado pela coordenadora da escola que ele será responsável por ministrar um curso sobre autocracia em um projeto com duração de uma semana, ao que ele tem uma reação negativa, já que sua vontade era ministrar o curso sobre anarquia - tema pelo qual tem um interesse pessoal. Durante o filme são discutidas diversas formas de ideologias e formas de governo, como o fascismo, o anarquismo, a autocracia e o nazismo.

A palavra autocracia deriva do grego e significa autogoverno (auto $=$ próprio $\mathrm{e}$ kratia $=$ poder). Nesse tipo de governo, o indivíduo ou o grupo que lidera tem poder ilimitado para mudar as leis às quais deve obedecer a massa dominada. Ao questionar a classe sobre as formas de governo, Wenger gera muita discussão entre os alunos e elege, durante as suas aulas, um método de ensino de simulação de um governo ditatorial. Inicialmente pareceu uma boa ideia, no entanto, os alunos envolvidos, fascinados com a

3. A primeira versão do filme foi produzida nos Estados Unidos (EUA), realizada para a televisão e bastante veiculada em cursos de licenciatura para formação de educadores. A refilmagem alemã é mais elaborada do que a versão anterior, além de trazer o assunto para o próprio cenário alemão e para a época atual. Ron Jones colaborou com Dennis Gansel para a realização do filme (http://www.fae.ufmg.br/setimaarte/images/pdf/a-onda. pdf). 
simulação e no auge da emoção, apresentaram fragilidades quanto à formação da identidade, suas intenções, que até mesmo ultrapassaram os muros da escola quando um aluno da turma, em um ato de desespero, comete suicídio.

O filme apresenta as razões que podem levarà alienação política eao cultivo de lideranças autoritárias, como o vazio de identidade, o consumismo desenfreado presente na sociedade capitalista, a ausência de projetos coletivos e o desinteresse das pessoas pela área da política.

Após a exibição, foi possível problematizar as questões e debater sobre a temática com os participantes. As reflexões remeteram ao resgate de posturas políticas amparadas pelo marxismo e que são, aqui, esmiuçadas em suas relações. Vejamos:

$\mathrm{Na}$ Alemanha, o partido comunista luta junto com a burguesia sempre que esta assume uma posição revolucionária contra a monarquia absoluta, a propriedade fundiária e a pequena burguesia. Mas, em momento algum o partido comunista deixa de despertar nos operários uma consciência clara e nítida do antagonismo violento entre a burguesia e o proletariado, para que os operários alemães na hora aprazada saibam converter as condições políticas e sociais criadas pelo regime burguês em outras tantas armas contra a burguesia, a fim de que, tão logo tenham sido destruídas as classes reacionárias da Alemanha, possa começar a luta contra a própria burguesia. (MARX; ENGELS, 2009, p. 102).

Neste sentido, as reflexões foram direcionadas para preencher as lacunas deixadas pelo capitalismo em nossa subjetividade profissional e pessoal.

Após a exibição do filme, as reflexões decorrentes da indignação visível da maioria dos participantes - foram colocadas para a mesa composta por dois professores, que coordenaram osquestionamentosemformadedebatereflexivo.

Muitas perguntas abrangeram o conceito de comunismo/anarquismo e sua relação com a ação do professor (protagonista principal do filme), que assumiu postura política radical frente aos alunos, o que, por sua vez, influenciou na aprendizagem do conceito e até mesmo a realidade cotidiana dos alunos.

\section{Última parada 174}

Com o intuito de problematizar a realidade brasileira, partiu-se o relato da segunda exibição. Trata-se da película intitulada Última parada 174, do diretor Bruno Barreto. O filme retrata a história do assaltante Sandro, que por cinco horas dominou os passageiros do ônibus 174. O filme não trata do sequestro em si, mas sim da história de vida do assaltante, ressaltando a perspectiva da desigualdade social de opressão e discriminação juvenil por meio da visualização de crianças e adolescentes em situação de vulnerabilidade social.

OArt.227 daConstituiçãoFederal prevêque

É dever da família, da sociedade e do Estado assegurar à criança, ao adolescente e ao jovem, com absoluta prioridade, o direito à vida, a saúde, a alimentação, a educação, ao lazer, a profissionalização, a cultura, a dignidade, ao respeito, a liberdade, e a convivência familiar e comunitária, além de coloca-los a salvo de toda forma de negligência, discriminação, exploração, violência, crueldade e opressão. (BRASIL, 1998).

Percebe-se uma enorme distância no cumprimento dessas diretrizes, pois não há um controle do Estado e nem políticas educacionais de subvenção à pauperização de crianças e adolescentes, que crescem sem proteção governamental e atenção integral. Em contrapartida, o Estatuto da Criança e do Adolescente (ECA), em seu artigo 4응 fundamenta a doutrina, a proteção integral da criança e a execução de políticas públicas sociais com essa finalidade última. Mesmo com o amparo da legislação educacional, muitos desafios ainda necessitam ser enfrentados 
para se vislumbrar outra realidade possível. Nessa mesma direção, temos os apontamentos sugestivos de Mészaros (2008) para a adoção de um ponto de vista de enfrentamento e mudança radical à doutrinação, por meio de ideais capitalistas, direcionada à educação, o que chama a atenção para a adoção da seguinte estratégia de ação:

Uma luta que jamais poderia ser levada a bom
termo, tanto porque não se pode vencer uma
força social poderosa pela ação fragmentada
de indivíduos isolados, como porque as
determinações estruturais causais da ordem
criticada devem ser rivalizadas e impugnadas
no domínio causal de referência: isto é, pela
força historicamente sustentável de uma
alternativa estrutural coerente. (MÉSZAROS,
2008, p. 86-87)

A adoção da perspectiva social radical, no caso explicitado no filme, seria a única alternativa para a eliminação das mazelas em que se encontra grande parcela do universo da infância.

Depois de concluída a projeção, as cenas marcantes nesses dois filmes, em apreciação no decorrer do ano de 2015, tomaram por fascínio trazer a tona o lugar da política na formação das narrativas históricas e até mesmo da memória da formação da sociedade brasileira. Com isso, modificou-se o olhar perante o papel das ações governamentais e das conjunturas que permeiam a instrumentalização das políticas públicas destinadas à educação em seus diferentes níveis e modalidades.

As opiniões expressas dos participantes evidenciaram grande preocupação em se problematizar, em outros momentos, as representações sociais que são sustentadas atualmente no contexto brasileiro de cunho excludente, desigual, doutrinário e ditatorial em suas relações socioinstitucionais. Portanto, o objetivo do marco-conceitual do projeto foi alcançado quando, no decorrer das reflexões, o alcance dessa problematização foi apreendido pela maioria dos seus participantes.
Para Carvalho e Carvalho (2013), a produção cinematográfica voltada para a educação com o intuito de produzir o movimento de análise e reflexão do que é memória, com atenção voltada para a sua complexidade, deve definir seus usos e suas apropriações condicionados a um fazer historiográfico enquanto representações do fato em si, lembrado e rememorado e, por último, recriado pela memória de determinado grupo. Portanto, o filme, como recurso didático e metodológico, estabelece diálogo estreito, não simplesmente no interesse de conhecer o passado, mas também e, sobretudo, sob a forma de revolução, reforma ou resistência.

Também é importante para a prática pedagógica que seja explicitada a realidade social de maneira autêntica e mais significativa possível para o educando. Freire (1979; 2000) afirma a necessidade de se repensar a dialogicidade da práxis, o seu fazer em sua proximidade com a realidade e suas ideologias, de modo a não influenciar o ensino com utopias e situações movidas pela falta de sentido da abordagem revolucionária que a educação possui.

\section{Catastroika}

A terceira projeção fílmica prevista contou com a exibição do documentário Catastroika, que consiste em um relato instigante sobre o impacto da privatização e da ideologia neoliberal no espaço e nos bens públicos em nosso cotidiano. As cenas são claras quanto às influências que os países em desenvolvimento receberam de instituições internacionais detentoras de certo poder e fluxo de capital.

A partir do documentário, nos foi possível desvendar os conceitos em torno das mutações do capitalismo na sociedade contemporânea e suas marcas no mercado financeiro, bolsa de valores, multinacionais, oligopólios e empresasrede. Toda a dinâmica de implementação de 
medidas financeiras que abalavam as estruturas democratizantes dos países foram elucidadas. Assim, as questões sobre crise política foram tema para debate após a exibição com a participação de professores e alunos da universidade.

A natureza econômica do trabalho pela ciência nesse documentário fora comprometida pela lógica do universo da economia, que assume duplo sentido, ou seja, o ganho político e/ou o ganho econômico ${ }^{4}$. O comprometimento reside em passar por cima das questões sociais que engendram as questões fundamentais das relações transnacionais, à multiplicação das inovações, o espaço cibernético, a transposição de barreiras geográficas, a criação de novos espaços, a ampliação do lucro, a racionalização da produção, a adaptação dos comportamentos às novas circunstâncias, o empreendedorismo, as microempresas, o crescimento do mercado informal, o fluxo do capital rentável, o ócio, o individualismo exacerbado, o consumismo, o incentivo ao entretenimento, o apego a futilidades, são apenas algumas características da natureza econômica do trabalho segundo o ponto de vista da mundialização do capital científico.

Muitas foram as questões de reflexão que enriqueceram as pesquisas em andamento no âmbito do grupo de pesquisa ao qual o projeto se vincula. O projeto se configurou como subsidio teórico-crítico e didático para o aprofundamento das questões mais candentes da política contemporânea e seus desdobramentos na educação e em específico na universidade pública brasileira. Em particular, nossa pesquisa foi subsidiada pelo documentário Catastroika à luz de seus conceitos sobre as medidas de austeridade na economia de países democráticos.

De acordo com Coelho et al. (2016), as escolhas das exibições cinematográficas do projeto foram criteriosas, pois resguardaram a necessidade primeira de trazer à tona o que tem ocorrido no cenário político atual, tanto nacional quanto internacional, para que a riqueza das reflexões e debates sejam acolhidas de maneira satisfatória entre os participantes.

No final das sessões, foi possível avaliar os avanços e retrocessos, e, por fim, chegar à conclusão que muitos foram os benefícios alcançados, visto que, os conhecimentos foram multiplicados e a cooperação de vários cursos pode realizar a confluência positiva de um debate interdisciplinar.

O papel do cinema foi, antes de tudo, humanizador para o espaço da universidade, o qual estimulou e motivou debates sobre a política atual e seus desdobramentos em pesquisa.

\section{Considerações finais}

Em uma sociedade de cinéfilos ${ }^{5}$, o uso das mídias voltadas para o ambiente da aprendizagem educacional tem se mostrado, segundo pesquisa, muito significativo. A prática de ver filmes tem ampliado os conhecimentos e desempenhado o papel de formação de pessoas. O caráter educativo do cinema tem se mostrado cada vez mais como tema de pesquisas educacionais, visto que, a criança pequena aprende mediante os estímulos visuais que recebe desde o seu nascimento. No entanto, ver e interpretar filmes implica, acima

4. Para Chesnais (2000, p. 9), "o fetichismo inerente à mercadoria e ao dinheiro parece ter sido contido durante algumas décadas com a ajuda das instituições sociais e políticas que comprimiram o capital em um quadro nacional. A mundialização do capital apresenta-se como sendo o quadro onde a relação social dos produtores no conjunto do processo do trabalho aparece mais uma vez e com uma força renovada como uma relação social externa a eles, uma relação entre objetos".

5. Pessoas que desenvolvem uma relação muito próxima com os filmes vêem de tudo, vão ao cinema regularmente, frequentam festivais, comentam entre amigos, sabem falar das técnicas cinematográficas, identificam diretores, tendências e movimentos. 
de tudo, perceber o significado que os filmes têm no contexto social no qual estão inseridos.

É justamente essa a oportunidade de participação que o projeto obteve nos encontros de exibições comentadas e analisadas. O caráter pedagógico articulado entre ficção e realidade entrelaçou as informações e os saberes das experiências de vida dos espectadores de cada filme ou documentário. Essa abordagem metodológica possibilitou o livre acesso a informações sobre representações sociais, infância, feminilidade, política, democracia, economia, segundo um ponto de vista muito singular de cada um.

A linguagem do cinema e audiovisual aprimora as competências dos saberes educacionais, instrumentaliza a formação e potencializa novas descobertas, na medida em que submete o professor e o aluno ao movimento da percepção mais abrangente do processo de significação das narrativas fílmicas.

Para Duarte (2002), o cinema na educação - compreendido como prática social, que une culturas em suas complexidades e desenvolve movimentos estéticos que criam novos pontos de vista perante a humanidade em sua pluralidade - é capaz de compor cenas e cenários imagéticos de experiências imagéticas que podem motivar um saber em prol de lutas democráticas, de paz mundial e de direitos humanos.

O presente projeto, em sua dimensão plural, contribuiu tanto para suscitar um novo olhar frente a desigualdade social educacional, a ponto de sensibilizar mudanças de ponto de vistas e de posturas no exercício da cidadania, quanto para a percepção científica desta autora no aprofundamento teórico das contradições e antagonismos sociais.

\section{REFERÊNCIAS}

A ONDA. Direção: Denis Gansel. Alemanha: Paramount Pictures, 2008. 1DVD (106min), son., color.

BRASIL. Constituição da República Federativa do Brasil. Brasília, DF, São Paulo: Saraiva, 1998.

CARVALHO, L. B. O. B; CARVALHO, C. H. História, cinema e educação: diálogos e entrelaçamentos entre política e memória por meio do filme "Escritores da liberdade". In: CARVALHO, C. H.; SOUZA, S. T.; RIBEIRO, B. de O. L. (Orgs.). Cinema e ensino de história da educação. Campinas, SP: Alínea, 2013. p. 229-249.

CATASTROIKA: Privatization Goes Public. Direção: Aris Chatzestefanou. Grécia, 2012. (87min), son., color..

COELHO, L. G, Z. et al. Formação política pela sétima arte: o cinema como prática pedagógica na Universidade Federal de Uberlândia no período de 2015-2016. In: Em Extensão, Uberlândia, v. 15, n. 2, p. 126-139, jul.-dez., 2016. doi: http://dx.doi.org/10.14393/REE-v15n22016_rel04.

CHESNAIS, F. A mundialização do capital. Tradução de Silvana Finzi Foá. São Paulo: Xamã, 1996. $335 \mathrm{p}$.

Mundialização: o capital financeiro no comando. Revista Outubro, São Paulo, n. 5, p. 7-28, 2000. Disponível em: < http://outubrorevista.com.br/wp-content/uploads/2015/02/RevistaOutubro-Edic\%CC\%A7a\%CC\%83o-5-Artigo-02.pdf>. Acesso em: 15 jun. 2017. 
DUARTE, R. Cinema e educação: refletindo sobre cinema e educação. Belo Horizonte: Autêntica, 2002. 126 p. (Coleção Temas e Educação).

LUKÁCS, G. Para uma ontologia do ser social. Tradução de Carlos Nelson Coutinho, Mario Duayer e Nélio Schneider. São Paulo: Boitempo, 2012. 845 p.

FREIRE, P. Pedagogia do oprimido. 6. Ed. Rio de Janeiro: Paz e terra, 1979. 253p.

Pedagogia da autonomia: saberes necessários à prática educativa. 15. ed. São Paulo: Paz e Terra, 2000. 165 p.

MARX, K. O capital: crítica da economia. 26. ed. Tradução de Reginaldo Santana. Rio de Janeiro: Civilização Brasileira, 2008. 571 p.

MARX, K.; ENGELS, F. Manifesto do Partido Comunista. Braga. São Paulo: Escala, 2009. 256 p.

MESZAROS, I. A educação para além do capital. 2. ed. Tradução de Isa Tavares. São Paulo: Boitempo, 2008. 125 p.

OLIVEIRA, Z. R. de. Educação infantil: fundamentos e métodos. 3.ed. São Paulo: Cortez, 2007. 265 p. (Coleção Docência em Formação).

ÚLTIMA PARADA: 174. Direção: Breno Barreto. Brasil, 2008. 1DVD (108 min).

Submetido em 24 de março de 2017.

Aprovado em 25 junho de 2017. 